\title{
Vascular cell responsiveness to Toll-like receptor ligands in carotid atheroma
}

C. Erridge* ${ }^{*}$ A. Burdess ${ }^{\dagger}$, A. J. Jackson ${ }^{\ddagger}$, C. Murray ${ }^{\#}$, M. Riggio ${ }^{\#}$, D. Lappin ${ }^{\#}$, S. Milligan $^{\#}$, C. M. Spickett ${ }^{\ddagger}$ and D. J. Webb ${ }^{\dagger}$

* Department of Cardiovascular Sciences, University of Leicester, Glenfield Hospital, Leicester, LE3 9QP

$\dagger$ The Queen's Medical Research Institute, University of Edinburgh, 47 Little France Crescent, Edinburgh, EH16 4TJ.

$\$$ Strathclyde Institute of Pharmacy and Biomedical Sciences, University of Strathclyde, 204 George Street, Glasgow, G1 1XW, UK

\# Infection and Immunity Research Group, Level 9, Glasgow Dental Hospital \& School, 378 Sauchiehall Street, Glasgow G2 3JZ, UK

Correspondence to: Clett Erridge, Department of Cardiovascular Sciences, University of Leicester, Glenfield Hospital, Leicester, LE3 9QP. Tel: +44 (0)116 256 3048. Fax: +44 (0)116287 5792. Email: ce55@leicester.ac.uk

Acknowledgements: These studies were supported by funding from the British Heart Foundation (FS/03/97) and the Strathclyde and Glasgow University Synergy Fund.

Running Head: Vascular cell responses to TLR ligands

Main text word count (introduction to discussion): 2,522 words, 13,958 characters 


\section{Abstract}

Background Atherosclerosis is potentiated by stimulation of Toll-like receptors (TLRs), which serve to detect pathogen-associated molecular patterns (PAMPs). However little is known of which PAMPs may be present in atheroma, or capable of stimulating inflammatory signalling in vascular cells.

Materials and Methods DNA extracted from human carotid atheroma samples was amplified and sequenced using broad-range 16S gene specific primers to establish historical exposure to bacterial PAMPs. Responsiveness of primary human arterial and venous endothelial and smooth muscle cells to PAMPs specific for each of the TLRs was assessed by measurement of interleukin- 8 secretion and E-selectin expression.

Results Extracts of atheromatous tissue stimulated little or no signalling in TLRtransfected HEK-293 cells. However, sequencing of bacterial DNA amplified from carotid atheroma revealed the presence of DNA from 17 different bacterial genera, suggesting historical exposure to bacterial lipopeptide, lipopolysaccharide and flagellin. All cells examined were responsive to the ligands of TLR3 and TLR4, polyinosine:cytosine and lipopolysaccharide. Arterial cells were responsive to a wider range of PAMPs than venous cells, being additionally responsive to bacterial flagellin and unmethylated cytosine-phosphate-guanosine DNA motifs, the ligands of TLR5 and TLR9 respectively. Cells were generally unresponsive towards the ligands of human TLR7 and TLR8, loxoribine and single stranded RNA. Only coronary artery endothelial cells expressed TLR2 mRNA and responded to the TLR2 ligand $\mathrm{Pam}_{3} \mathrm{CSK}_{4}$.

Conclusions Vascular cells are responsive to a relatively diverse range of TLR ligands and may be exposed, at least transiently, to ligands of TLR2, TLR4, TLR5 and TLR9 during the development of carotid atheroma.

Keywords: Atherosclerosis, Toll-like receptor, $16 \mathrm{~S}$ gene, bacteria 


\section{Introduction}

Atherosclerosis is a chronic inflammatory disease of the arteries, characterised by the activation of endothelial cells to express inflammatory mediators and the subsequent recruitment of monocytes into the artery wall, which may differentiate to form fat-laden foam cells [1]. Among candidate inflammatory stimuli that may potentiate this condition, stimulation of Toll-like receptors (TLRs) has emerged as a key factor in atherogenesis [2].

The ten human TLRs serve to initiate inflammatory signalling in response to the detection of conserved pathogen associated molecular patterns (PAMPs). TLR2, in conjunction with heterodimerisation partners TLR6 or TLR1, recognises di-acyl or triacyl bacterial lipopeptides (BLP), respectively. TLR3 recognises double stranded RNA, while TLRs 7 and 8 recognise single stranded RNA motifs, indicating a role for these receptors in anti-viral defence [3]. TLRs 4, 5 and 9 recognise bacterial lipopolysaccharide (LPS), flagellin and the unmethylated cytosine-phosphate-guanosine (CpG) DNA motif, respectively, while no ligand has yet been identified for TLR10. In each case, engagement of TLRs with their respective ligands leads to the induction of inflammatory signalling and the resultant expression of inflammatory mediators such as interleukin (IL)-8, tumour necrosis factor (TNF)- $\alpha$ and E-selectin [4].

Mice deficient in a shared signalling adaptor of the TLRs, myeloid differentiation factor-88 (MyD88), have been shown to be resistant to atherogenesis [5,6], while genetic deletion of TLR2 or TLR4 also leads to a reduction in aortic plaque burden of between $30 \%$ and $60 \%$ in mouse models of atherosclerosis [5-8]. Accordingly, experimental 
stimulation of TLR2 or TLR4 signalling via recurrent injection of either BLP or LPS markedly accelerates atherogenesis [8-10]. In human atheromatous tissue, expression of TLRs 2, 4 and 5 is markedly upregulated compared to healthy artery, and TLR2 and TLR4-expressing cells within plaque were shown to co-stain for activated nuclear factor $(\mathrm{NF})-\kappa \mathrm{B}[11]$.

The likely stimulants of TLRs in the diseased artery wall remain to be clearly identified. However, as many previous studies have reported the presence of bacterial products within human atheroma [12-15], and seropositivity to common viruses has also been associated with atherosclerosis $[16,17]$, it is likely that vascular cells may be exposed to diverse TLR ligands of both bacterial and viral origin during the development of atheroma.

As little information exists on the responsiveness of primary human vascular cells to PAMPs specific for each of the TLRs, and since arterial tissues are more susceptible to the development of atherosclerosis than venous tissues, we aimed to establish the range of TLR-ligands that may be capable of stimulating expression of IL- 8 and E-selectin in primary venous and arterial endothelial and smooth muscle cells, and sought evidence for the presence of these PAMPs in human atheromatous tissue.

\section{Materials and Methods}

\section{Culture of primary vascular cells}

Vein rings from healthy saphenous vein harvested for coronary artery bypass graft were cultured in 50:50 Waymouths:F12/Ham solution (Invitrogen, Paisley, UK) in 15\% Foetal 
Calf Serum. Explanted human vein smooth muscle cells (HVSMC) were split using trypsin/EDTA (Sigma, Poole, UK) and transferred to $75 \mathrm{~cm}^{2}$ tissue culture flasks for use between passages 1 and 3. Collection of venous tissue was performed with informed consent in accordance with local ethical guidelines (REC \# 07/S0704/48). Human primary aortic (HAEC) and umbilical vein (HUVEC) endothelial cells and arterial smooth muscle cells (HASMC) were purchased from Cascade Biologics (Paisley, UK) and cultured in M200 medium, or M231 according to supplier's recommendations. Human primary coronary artery endothelial cells (HCAEC) were purchased from Cambrex (East Rutherford, USA) and cultured in EGM2-MV according to supplier's recommendations. In each case, cells were cultured in $5 \% \mathrm{CO} 2$ at $37^{\circ} \mathrm{C}$ and were used for experiments between passages 3 and 7 .

\section{Challenge of vascular cells with PAMPs}

$\mathrm{Pam}_{3} \mathrm{CSK}_{4}$, PolyI:C, Bacillus subtilis flagellin, loxoribine, single stranded RNA and endotoxin-free bacterial CpG DNA were from Invivogen (Toulouse, France). LPS of Escherichia coli R1 (NCTC 13114) and Porphyromonas gingivalis was a kind gift of Professor Ian Poxton (University of Edinburgh). Vascular cells were plated at $2 \times 10^{4}$ cells per well of 96-well plates and allowed to adhere for $24 \mathrm{~h}$ prior to challenge. Cells were then challenged with medium alone (DMEM containing $1 \%$ serum), $100 \mathrm{ng} / \mathrm{ml}$ $\mathrm{Pam}_{3} \mathrm{CSK}_{4}, 25 \mu \mathrm{g} / \mathrm{ml}$ PolyI:C, $100 \mathrm{ng} / \mathrm{ml} \mathrm{LPS}, 1 \mu \mathrm{g} / \mathrm{ml}$ flagellin, $1 \mathrm{mM}$ loxoribine, 5 $\mu \mathrm{g} / \mathrm{ml}$ single stranded RNA or $10 \mu \mathrm{g} / \mathrm{ml} \mathrm{CpG} \mathrm{DNA}$, in triplicate wells. After $18 \mathrm{~h}$, culture supernatant was assessed for IL-8 concentration by ELISA (R\&D Duoset, Minneapolis, USA). Alternatively, endothelial cells were cultured with PAMPs for $4 \mathrm{~h}$ before 
measurement of cell-surface E-selectin expression. In other experiments, J774A.1

macrophages were challenged with the same concentrations of PAMPs and supernatant TNF- $\alpha$ was measured at 4 h by L929 bioassay [18].

\section{Cell-based E-selectin ELISA}

HUVECs, HAECs and HCAECs treated with PAMPs for 4h in 96-well plates were washed twice in phosphate-bufffered saline (PBS) and fixed with $4 \%$ paraformaldehyde in PBS at $4^{\circ} \mathrm{C}$ for 15 minutes. Wells were then washed twice in PBS and blocked with $1 \%$ bovine serum albumin in PBS for 30 minutes. Plates were washed three times, and biotinylated E-selectin-specific antibody (Hycult Biotechnology, Uden, Netherlands), was added to each well at a concentration of $500 \mathrm{ng} / \mathrm{ml}$ in reagent diluent $(20 \mathrm{mMTris}$, $150 \mathrm{mM} \mathrm{NaCl}, 0.1 \%$ BSA, 0.05\% Tween-20). Wells were then washed and 1:200 dilution of streptavidin-horse-radish peroxidase $(R \& D)$ in reagent diluent was added for 30 minutes. Wells were then washed and $100 \mu \mathrm{l}$ of 3,3',5,5-tetramethylbenzidine reagent (Sigma) added. Absorbance of each well was measured at $450 \mathrm{~nm}$ using a spectrophotometer.

\section{TLR RT-PCR}

RNA was prepared from $1 \times 10^{6}$ vascular cells plated in 6-well tissue culture plates using an RNEasy kit (Qiagen, Crawley, UK). cDNA was prepared from extracted RNA using oligo-dT primer and reverse transcriptase (Stratagene, La Jolla, USA). For PCR amplification of cDNA specific for $\beta$-actin or TLRs $1-9,1 \mu \mathrm{l}$ of cDNA was amplified in a $30 \mu \mathrm{l}$ reaction volume using Go-Taq reaction master mix (Promega, Southampton, UK). 
Thermal cycling consisted of 3 minutes at $94^{\circ} \mathrm{C}$, followed by 27 cycles of $94^{\circ} \mathrm{C}$ for $30 \mathrm{~s}$, $55^{\circ} \mathrm{C}$ for $30 \mathrm{~s}$ and $72^{\circ} \mathrm{C}$ for $1 \mathrm{~min}$ and a final extension at $72^{\circ} \mathrm{C}$ for 10 minutes. The primers used to amplify each target gene are listed in Table 1.

\section{S PCR identification of bacterial DNA in atheromatous tissue}

Atheromatous plaques $(\mathrm{n}=3)$ were obtained from routine carotid endarterectomy, performed due to transient ischaemic attack, with informed consent according to local ethical procedures (LREC 04/S1101/48). Care was taken to avoid contamination of the excised material which was stored at $-20^{\circ} \mathrm{C}$ prior to analysis. Plaque tissue was homogenised with $1.0 \mathrm{~mm}$ glass beads in a mini beadbeater (Biospec, Bartlesville, USA) before lysis and DNA extraction using TRIzol reagent (Sigma). PCR was then performed using consensus primers $27 \mathrm{f}$ and $1387 \mathrm{r}$ that amplify the $16 \mathrm{~S}$ rRNA gene of diverse bacteria, as described previously [19]. A positive control PCR containing $10 \mathrm{ng}$ of E. coli genomic DNA was included in each experiment. PCR products were cloned using the TOPO TA Cloning Kit (Invitrogen), and selected clones were sequenced in one direction using the $357 \mathrm{~F}$ primer to obtain a minimum of $500 \mathrm{bp}$ of sequence from a variable region of the $16 \mathrm{~S}$ rRNA gene. All clone sequences were then compared against the EMBL/GenBank sequence databases using the BLAST algorithm. Clones sharing $98 \%$ identity with a known sequence were positively identified as belonging to that species. Sequences with a lower percentage identity were analysed using the PHYLIP suite of programmes to determine the phylogenetic position of the clone. For all 16S-work, strict anti-contamination procedures were employed. Separate rooms were used for sample preparation, PCR reactions and analysis of reaction products. Filter tips were used at all 
stages and for each set of samples being analysed and negative controls (sterile water) were included.

\section{TLR-transfection assay}

HEK-293 cells were plated in 96-well plates at $2 \times 10^{4}$ cells per well and transfected after 24 h using Genejuice (Novagen, Nottingham, UK), with 30 ng of human TLRs 2, 4 (coexpressing MD-2), or 5 (Invivogen), $30 \mathrm{ng}$ of pCD14, $10 \mathrm{ng}$ of NF- $\mathrm{kB}$ sensitive luciferase-reporter construct (pELAM) and $20 \mathrm{ng}$ of renilla-luciferase reporter construct [20]. Three days after transfection, cells were challenged for $18 \mathrm{~h}$ with PAMPs or atheroma samples. Reporter levels were measured using Promega Dual-Glo reagent kit and normalised to co-transfected renilla expression. Promoter expression is represented as fold induction relative to cells cultured in medium alone +/- SD. Human carotid atheroma samples were ground under liquid nitrogen in sterile cryovials before resuspension in 10 volumes (per weight) of DMEM / 1\% foetal calf serum (FCS) prior to sonication for 2 minutes, vortexing for 2 minutes and addition to transfected cells.

\section{Results}

\section{Responsiveness of primary vascular cells to TLR ligands}

Primary human vascular cells were exposed to PAMPs specific for each of the functional human TLRs at concentrations that were found to induce maximal induction of TNF- $\alpha$ secretion in TLR-competent macrophages (Figure 1), or as described previously [21]. Secretion of IL-8 and expresssion of E-selectin were measured as markers of cellular 
inflammatory activation as these mediators have been implicated in the progression of atherosclerosis in previous studies [22,23]. A significant increase in IL-8 secretion was observed from venous SMCs in response to LPS and PolyI:C and from venous ECs in response to LPS, PolyI:C and CpG DNA, but not other PAMPs (Figure 2). Arterial ECs and SMCs exposed to the same ligands increased IL-8 secretion in response to treatment with PolyI:C, LPS, flagellin and CpG DNA (Figure 3). Significant upregulation of Eselectin expression by arterial ECs was observed in response to LPS, PolyI:C and flagellin, while an E-selectin response was observed in venous ECs exposed to only PolyI:C or LPS (Figure 4). Only coronary artery ECs responded to $\mathrm{Pam}_{3} \mathrm{CSK}_{4}$ stimulation with increased IL-8 secretion and E-selectin expression.

\section{Qualitative analysis of TLR mRNA expression by vascular cells}

In order to establish whether mRNA corresponding to each of the TLRs was expressed in primary vascular cells, qualitative RT-PCR was performed using primers specific for each of the 9 functional TLRs (Figure 5). HUVECs expressed detectable mRNA for all TLRs other than TLR2. HAECs and HASMCs expressed mRNA for all TLRs other than TLR1 and TLR2, while HVSMCs expressed mRNA for all TLRs other than TLR1, TLR2 or TLR7. Remarkably, HCAECs expressed mRNA specific for all of the 9 TLRs examined. THP-1 macrophages were found to express detectable mRNA for all TLRs other than TLR3. No bands were detected from PCR reactions containing RNA that had not been reverse transcribed (data not shown).

\section{Investigation of bacterial 16S DNA signatures in human carotid atheroma}


In order to gain information on the potential prior exposure of atheromatous tissue to bacterial ligands of the TLRs, DNA was extracted from three atheromatous plaques and amplified by PCR using primers specific for the bacterial 16S DNA gene. 58 cloned PCR products were sequenced, of which 56 could be identified to bacterial genus or species level. The most frequently isolated clones corresponded to Acinetobacter species, followed by Brevundimonas species and Lysobacter enzymogenes. A further 14 bacterial genera were identified at lower frequencies (Table 2). No amplification product was detected in control experiments using identical reagents with sterile water replacing template DNA.

\section{Biological activity of TLR2, TLR4 and TLR5 ligands in human atheroma}

Given the likelihood that developing plaques are at some stage exposed to ligands of TLR2, TLR4 and TLR5, we next aimed to determine whether such PAMPs may remain detectable in human atheroma. To achieve this, endarterectomy samples were homogenised and applied to HEK-293 cells transfected with NF-kB-sensitive reporter and TLR2, TLR4 or TLR5. P. gingivalis LPS, E. coli LPS and flagellin were detected only in cells expressing TLR2, TLR4 or TLR5, respectively, confirming the purity of these reagents and also the specificity of the TLR-reporter assay (Figure 6A). No stimulants of TLR4 or TLR5 could be detected in the atheroma samples, although in one plaque sample there was a significant increase in reporter activity in cells expressing TLR2, but not other TLRs, indicating the presence of a TLR2 ligand in this sample (Figure 6B). 


\section{Discussion}

Since the observation that TLR-signalling is a key modulator of atherosclerosis in animal models [5-10], two main questions that remain to be addressed in this area are: what is the range of TLR-ligands that may stimulate inflammatory signalling in human vascular cells, and what might be responsible for stimulating TLR-signalling in human atheromatous tissue?

Our results suggest that arterial cells are responsive to a relatively wide range of PAMPs, particularly those derived from bacteria, including ligands of TLRs 2, 4, 5 and 9. Notably, the identification of responsiveness of arterial cells to flagellin appears to be novel, and adds weight to previous reports of TLR5 protein expression in internal mammary artery and intestinal microvessels $[11,24]$. Uniquely among the vascular cell types examined, endothelial cells from the coronary artery also expressed TLR2 and were responsive to bacterial lipopeptide, in accordance with previous reports $[25,20]$. The observation that arterial cells are responsive to a wider range of bacterial PAMPs than venous cells may be of relevance regarding the increased susceptibility of arteries to plaque formation compared to veins, as chronic bacterial infection has been reported to correlate with increased atherosclerosis risk [26,27], and immunohistochemical approaches have revealed the presence of diverse bacterial antigens in a high percentage of atheroma samples [13,28-30].

We next aimed to examine the possibility that atheromatous tissues may be exposed to the bacterial ligands of the receptors we identified to be functional in arterial tissues in this study, namely TLRs 2, 4, 5 and 9. Although extracts from atheromatous samples stimulated no TLR4- or TLR5-dependent signalling in the TLR-transfection assays, we 
cannot exclude the possibility that small numbers of bacteria expressing LPS or flagellin may nevertheless be present in the samples as the limit of sensitivity of the assay is around $10^{3}$ bacterial cells per $\mathrm{ml}$. It is more likely, however, that biologically active PAMPs delivered to the artery wall exert their atherogenic properties only transiently, being soon degraded and thereby losing their inflammatory potential, such as by proteolysis of flagellin or deacylation of LPS [31]. Indeed, an emerging consensus is that bacterial antigens and DNA, rather than live bacteria, accumulate within atheroma $[12,13,32]$.

Seeking alternative evidence of exposure of atheroma to bacterial PAMPs, we examined bacterial 16S DNA signatures from atheroma, as 16S gene containing DNA fragments have been shown to remain intact for years in tissues after degradation of other bacterial macromolecules [33]. Confirming the results of several recent studies, we found an abundant diversity of bacterial 16S DNA signatures in human atheroma, extending the list of species discovered in atheroma to include Acinetobacter and Brevundimonas species $[14,15,30,34-36]$. Notably, all of the bacteria identified in this and previous studies are thought to express ligands of TLR2 and TLR9, while endotoxin of Acinetobacter species stimulates TLR4-signalling and approximately half of the genera identified in our study are thought to be motile and express flagellin (Table 2). The 16S data therefore supports the notion that during the development of human atheroma, such tissues may be exposed, at least transiently, to ligands of TLR2, TLR4, TLR5 and TLR9. In summary, we have shown that arterial cells are typically responsive to a wider range of PAMPs than venous cells and that it is likely that arterial cells may be exposed, at least transiently, to bacterial ligands of TLRs 2, 4, 5 and 9 during the development of carotid 
atheroma. While the observations presented here do not allow any conclusion to be drawn as to whether or not bacteria potentiate atherosclerosis, it seems likely that if this is the case, no single organism or source of bacterial antigens is likely to be identified as a unique contributor to atherogenesis. 


\section{References}

1 Ross R. Atherosclerosis is an inflammatory disease. Am Heart J 1999;138:S419-20.

2 Tobias P, Curtiss LK. Thematic review series: The immune system and atherogenesis. Paying the price for pathogen protection: toll receptors in atherogenesis. J Lipid Res 2005;46:404-11.

3 Alexopoulou L, Holt AC, Medzhitov R, Flavell RA. Recognition of double stranded RNA and activation of NF-kB by Toll-like receptor 3. Nature 2001;413:732-8.

4 McGettrick AF, O'Neill LA. The expanding family of MyD88-like adaptors in Toll-like receptor signal transduction. Mol Immunol 2004;41:577-82.

5 Bjorkbacka H, Kunjathoor VV, Moore KJ, Koehn S, Ordija CM, Lee MA, et al. Reduced atherosclerosis in MyD88-null mice links elevated serum cholesterol levels to activation of innate immunity signalling pathways. Nat Med 2004; 10:416-21.

6 Michelson KS, Wong MH, Shah PK, Zhang W, Yano J, Doherty TM, et al. Lack of Toll-like receptor 4 or myeloid differentiation factor 88 reduces atherosclerosis and alters plaque phenotype in mice deficient in apolipoprotein E. Proc Natl Acad Sci USA 2004;101:10679-84.

7 Liu X, Ukai T, Yumoto H, Davey M, Goswami S, Gibson III FC, et al. Tolllike receptor 2 plays a critical role in the progression of atherosclerosis that is independent of dietary lipids. Atherosclerosis 2008; 196:146-54. 
8 Mullick AE, Tobias PS, Curtiss LK. Modulation of atherosclerosis in mice by Toll-like receptor 2. J Clin Invest 2005;115:3149-56.

9 Lehr HA, Sagban TA, Ihling C, Zahringer U, Hungerer KD, Blumrich M, et al. Immunopathogenesis of atherosclerosis: endotoxin accelerates atherosclerosis in rabbits on hypercholesterolemic diet. Circulation 2001;104:914-20.

10 Schoneveld AH, Oude Nijhuis MM, van Middelaar B, Laman JD, de Kleijn DP, Pasterkamp G. Toll-like receptor 2 stimulation induces intimal hyperplasia and atherosclerotic lesion development. Cardiovasc Res 2005;66:162-9.

11 Edfeldt K, Swedenborg J, Hansson GK, Yan Z. Expression of Toll-like receptors in human atherosclerotic lesions: A possible pathway for plaque activation. Circulation 2002;105:1158-60.

12 Laman JD, Schoneveld AH, Moll FL, van Meurs M, Pasterkamp G. Significance of peptidoglycan, a proinflammatory bacterial antigen in atherosclerotic arteries and its association with vulnerable plaques. Am J Cardiol 2002;90:119-23.

13 Meijer A, Roholl PJ, Gielis-Proper SK, Ossewaarde JM. Chlamydia pneumoniae antigens, rather than viable bacteria, persist in atherosclerotic lesions. J Clin Pathol 2000;53:911-6.

14 Ott SJ, El Mokhtari NE, Musfeldt M, Hellmig S, Freitag S, Rehman A, et al. Detection of diverse bacterial signatures in atherosclerotic lesions of patients with coronary heart disease. Circulation 2006;113:929-37.

15 Lehtiniemi J, Karhunen PJ, Goebeler S, Nikkari S, Nikkari ST. Identification of different bacterial DNAs in human coronary arteries. Eur J Clin Invest 
2005;35:13-6.

16 Grattan MT, Moreno-Cabral CE, Starnes VA, Oyer PE, Stinson EB, Shumway

NE. Cytomegalovirus infection is associated with cardiac allograft rejection and atherosclerosis. JAMA 1989;261:3561-6.

17 Sorlie PD, Nieto FJ, Adam E, Folsom AR, Shahar E, Massing M. A prospective study of cytomegalovirus, herpes simplex virus 1 , and coronary heart disease: The Atherosclerosis Risk in Communities (ARIC) study. Arch Intern Med 2000;160:2027-32.

18 Delahooke, D., Barclay, G., Poxton, I. TNF- $\alpha$ induction by an aqeous phenolextracted lipopolysaccharide complex from Bacteroides species. Infect Immun $1996 ; 63: 840-6$.

19 Dempsey KE, Riggio MP, Lennon A, Hannah VE, Ramage G, Allan D, et al. Identification of bacteria on the surface of clinically infected and non-infected prosthetic hip joints removed during revision arthroplasties by $16 \mathrm{~S}$ rRNA gene sequencing and by microbiological culture. Arthritis Res Ther 2007;9:R46.

20 Erridge C, Spickett CM, Webb DJ. Non-enterobacterial endotoxins stimulate human coronary artery but not venous endothelial cell activation via Toll-like receptor 2. Cardiovasc Res 2007;73:181-9.

21 Gorden KB, Gorski KS, Gibson SJ, Kedl RM, Kieper WC, Qiu X, et al. Synthetic TLR agonists reveal functional differences between human TLR7 and TLR8. J Immunol 2005;174:1259-68.

22 Boekholdt SM, Peters RJ, Hack CE, Day NE, Luben R, Bingham SA, et al. IL8 plasma concentrations and the risk of future coronary artery disease in 
apparently healthy men and women: the EPIC-Norfolk prospective population study. Arterioscler Thromb Vasc Biol 2004;24:1503-8.

23 Collins RG, Velji R, Guevara NV, Hicks MJ, Chan L, Beaudet AL. P-Selectin or intercellular adhesion molecule (ICAM)-1 deficiency substantially protects against atherosclerosis in apolipoprotein E-deficient mice. $J$ Exp Med 2000;191:189-94.

24 Maaser C, Heidemann J, Eiff CV, Lugering A, Spahn TW, Binion DG, et al. Human intestinal microvascular endothelial cells express Toll-like receptor 5: A binding partner for bacterial flagellin. J Immunol 2004;172:5056-62.

25 Dunzendorfer S, Lee HK, Tobias PS. Flow-dependent regulation of endothelial Toll-like receptor 2 expression through inhibition of SP1 activity. Circ Res 2004;95:684-91.

26 Kiechl S, Egger G, Mayr M, Wiedermann CJ, Bonora E, Oberhollenzer F, et al. Chronic infections and the risk of carotid atherosclerosis prospective results from a large population study. Circulation 2001;103:1064-70.

27 Mayr M, Kiechl S, Willeit J, Wick G, Xu Q. Infections, immunity, and atherosclerosis: associations of antibodies to Chlamydia pneumoniae, Helicobacter pylori, and cytomegalovirus with immune reactions to heat-shock protein 60 and carotid or femoral atherosclerosis. Circulation 2000;102:833-9.

28 Juvonen J, Juvonen T, Laurila A, Alakarppa H, Lounatmaa K, Surcel HM, et al. Demonstration of Chlamydia pneumoniae in the walls of abdominal aortic aneurisms. J Vasc Surg 1997;25:499-505.

29 Vink A, Poppen M, Schoneveld AH, Roholl PJM, de Kleijn DPV, Borst C, et 
al. Distribution of Chlamydia pneumoniae in the human arterial system and its relation to the local amount of atherosclerosis within the individual. Circulation 2001;103:1613-7.

30 Fiehn NE, Larsen T, Christiansen N, Holmstrup P, Schroeder TV. Identification of periodontal pathogens in atherosclerotic vessels. J Periodontol 2005;76:7316.

31 Erwin AL, Munford RS. Deacylation of structurally diverse lipopolysaccharides by human acyloxyacyl hydrolase. J Biol Chem 1990;265:16444-9.

32 Poppert S, Schlaupitz K, Marre R, Voisard R, Roessler W, Weckermann D, et al. Chlamydia pneumoniae in an ex vivo human artery culture model. Atherosclerosis 2006;187:50-6.

33 van der Heijden IM, Wilbrink B, Tchetverikov I, Schrijver IA, Schouls LM, Hazenberg MP, et al. Presence of bacterial DNA and bacterial peptidoglycans in joints of patients with rheumatoid arthritis and other arthritides. Arth Rheum 2000;43:593-8.

34 Kozarov E, Sweier D, Shelburne C, Progulske-Fox A, Lopatin D. Detection of bacterial DNA in atheromatous plaques by quantitative PCR. Microbes Infect 2006;8:687-93.

35 Okuda K, Ishihara K, Nakagawa T, Hirayama A, Inayama Y, Okuda K. Detection of Treponema denticola in atherosclerotic lesions. J Clin Microbiol 2001;39:1114-7.

36 Renko J, Lepp PW, Oksala N, Nikkari S, Nikkari ST. Bacterial signatures in 
atherosclerotic lesions represent human commensals and pathogens.

Atherosclerosis 2008;doi:10.1016/j.atherosclerosis.2008.01.006. 
Figure legends

Figure 1: Tumour necrosis factor (TNF)- $\alpha$ secretion from J774A.1 macrophages exposed to pathogen associated molecular patterns (PAMPs)

J774A.1 macrophages were challenged with medium alone (Ctrl), $\mathrm{Pam}_{3} \mathrm{CSK}_{4}(\mathrm{Pam} 3)$, Poly-Inosine:Cytosine (PolyI:C), lipopolysaccharide (LPS), flagellin (Flag), Loxoribine (Lox), single stranded RNA (ssRNA) or cytosine-phosphate-guanosine (CpG) DNA at the concentrations indicated in the materials and methods. Supernatant TNF- $\alpha$ was measured after $4 \mathrm{~h}$. Results are presented as mean +/- SD of triplicate wells and are representative of four independent experiments. $* * \mathrm{P}<0.01$ vs cells cultured in medium alone.

Figure 2: Interleukin (IL)-8 secretion from human umbilical vein endothelial cells (HUVECs) and human venous smooth muscle cells (HVSMCs) exposed to PAMPs HUVECs (A) and HVSMCs (B) were challenged with medium alone (Ctrl), $\mathrm{Pam}_{3} \mathrm{CSK}_{4}$ (Pam3), PolyI:C, LPS, flagellin (Flag), Loxoribine (Lox), single stranded RNA (ssRNA) or CpG DNA at the concentrations indicated in the materials and methods. IL-8 secretion was measured after $18 \mathrm{~h}$. Results are presented as mean +/- SD of triplicate wells and are representative of three independent experiments. $* * \mathrm{P}<0.01$ vs cells cultured in medium alone. 
Figure 3: IL-8 secretion from human aortic endothelial cells (HAECs), coronary artery endothelial cells (HCAECs) and arterial smooth muscle cells (HASMCs) exposed to PAMPs

HAECs (A), HCAECs (B) and HASMCs (C) were challenged with PAMPs as described in the legend to Figure 1. IL-8 secretion was measured after $18 \mathrm{~h}$. Results are presented as mean $+/-$ SD of triplicate wells and are representative of three independent experiments. * $\mathrm{P}<0.05$ vs cells cultured in medium alone.

\section{Figure 4: E-selectin expression by HAECs and HUVECs exposed to PAMPs} HAECs (A), HCAECs (B) and HUVECs (C) were challenged with PAMPs as described in the legend to Figure 1. Expression of E-selectin was measured by cell-surface ELISA after 4 h. Results are presented as mean +/- SD of triplicate wells and are representative of at least two independent experiments. $* \mathrm{P}<0.05$ vs cells cultured in medium alone.

Figure 5: Qualitative analysis of Toll-like receptor (TLR) mRNA expression in vascular cells

cDNA from primary human vascular cells or THP-1 macrophages was subjected to PCR (27 cycles) using primers specific for $\beta$-actin ( $\beta$ ), or TLRs 1-9, as indicated. Products were single and of the expected size.

\section{Figure 6: TLR-assay of extracts from atheromatous plaques}

HEK-293 cells were transfected with nuclear factor $\kappa B$ sensitive promoter construct (pELAM) and CD14 alone, or with additional TLR2, TLR4/MD2 or TLR5. Transfected 
cells were then challenged with $100 \mathrm{ng} / \mathrm{ml} P$. gingivalis LPS, $100 \mathrm{ng} / \mathrm{ml}$ E. coli LPS or 1 $\mu \mathrm{g} / \mathrm{ml}$ B. subtilis flagellin (A). Alternatively, transfected cells were exposed to homogenate from human carotid atheromatous tissue ground under liquid nitrogen and resuspended at 1:10 (weight:volume) in DMEM / 1\% FCS (B). Promoter expression was then measured at $18 \mathrm{~h}$ and is represented as fold induction relative to cells cultured in medium alone $+/-\mathrm{SD}$. Results shown are representative of three separate experiments. ** $\mathrm{P}<0.01$ vs cells cultured in medium alone. 
Table 1: Primers used for RT-PCR and 16S directed sequencing

\begin{tabular}{|c|c|c|}
\hline$\underline{\text { Gene }}$ & $\underline{\text { Primer Sequence }}$ & $\underline{\text { Product size }}$ \\
\hline \multirow[t]{2}{*}{$\beta$-actin } & TACCCCATCGAGCACGGCA & $289 \mathrm{bp}$ \\
\hline & TGGGCACAGTGTGGGTGAC & \\
\hline \multirow[t]{2}{*}{ TLR1 } & GCATCTTCCATTTTGCCATT & $304 \mathrm{bp}$ \\
\hline & TTGTTGTGGGACAAATCCAA & \\
\hline \multirow[t]{2}{*}{ TLR2 } & GGCCAGCAAATTACCTGTGT & $320 \mathrm{bp}$ \\
\hline & CTCCAGCTCCTGGACCATAA & \\
\hline \multirow[t]{2}{*}{ TLR3 } & AGCCGCCAACTTCACAAG & $327 \mathrm{bp}$ \\
\hline & AGCTCTTGGAGATTTTCCAGC & \\
\hline \multirow[t]{2}{*}{ TLR4 } & GGTGGGAATGCTTTTTCAGA & $358 \mathrm{bp}$ \\
\hline & AATTGCCAGCCATTTTCAAG & \\
\hline \multirow[t]{2}{*}{ TLR5 } & CATGACCATCCTCACAGTCACAAAG & 365 bp \\
\hline & GGGCATAACTGAAGGCTTCAAGG & \\
\hline \multirow[t]{2}{*}{ TLR6 } & CCTGCCCATCTGTAAGGAAT & $399 \mathrm{bp}$ \\
\hline & CTGACCAGGCATTTCCAAGT & \\
\hline \multirow[t]{2}{*}{ TLR7 } & TTGGCTTCTGCTCAAATGC & $300 \mathrm{bp}$ \\
\hline & CTAAAGGTTGGAATTCACTGCC & \\
\hline \multirow[t]{2}{*}{ TLR8 } & GTCGACTACAGGAAGTTCCCC & $260 \mathrm{bp}$ \\
\hline & GGGTAACTGGTTGTCTTCAAGC & \\
\hline \multirow[t]{2}{*}{ TLR9 } & GTGCCCCACTTCTCCATG & $260 \mathrm{bp}$ \\
\hline & GGCACAGTCATGATGTTGTTG & \\
\hline \multirow[t]{2}{*}{$16 \mathrm{~S}$} & AGAGTTTGATCMTGGCTCAG & $1,400 \mathrm{bp}$ \\
\hline & GGGCGGWGTGTACAAGGC & \\
\hline $357 \mathrm{~F}$ & CCTACGGGAGGCAGCAG & NA \\
\hline
\end{tabular}


Table 2: Bacterial species identified in human atheroma by 16S rDNA PCR

$\underline{\text { Clones }} \underline{\text { Percent }} \underline{\text { Species }}$

$24 \quad 41.4 \%$ Acinetobacter johnsonii/haemolyticus

$9 \quad 15.5 \% \quad$ Brevundimonas diminuta and sp.

$5 \quad 8.6 \quad$ Lysobacter enzymogenes

$2 \quad 3.5 \quad$ Pseudomonas putida

$2 \quad 3.5 \quad$ Bosea sp.

$2 \quad 3.5 \quad$ Ochrobactrum sp.

$2 \quad 3.5 \quad$ Delftia acidovorans

$1 \quad 1.7 \quad$ Brevibacterium casei

$1 \quad 1.7 \quad$ Agrobacterium sp.

$1 \quad 1.7 \quad$ Acidovorax sp.

$1 \quad 1.7 \quad$ E.coli, Salmonella or Shigella

$1 \quad 1.7 \quad$ Methylobacterium fujisawaense

$1 \quad 1.7 \quad$ Moraxella osloensis

$1 \quad 1.7 \quad$ Sphingomonas sp.

$1 \quad 1.7 \quad$ Eubacterium sp. / Acinetobacter sp.

$1 \quad 1.7 \quad$ Porphyrobacterium tepidarius

$1 \quad 1.7 \quad$ Uncultured beta proteobacterium

$2 \quad 3.5 \quad$ Unclassified clones
\% Identity Accession Motile

98.7 - $99 \quad$ AB099655 No

96.5 - $99 \quad$ DQ857897 Yes

$97.7 \quad$ AY074793 No

$99 \quad$ AF094741 Yes

97.5 - $99 \quad$ DQ440825 Yes

$98 \quad$ DQ989292 Yes

96-98 AM180725 Yes

98.6 AY468365 No

98.5 EF419343 Yes

$97.3 \quad$ AY755391 ?

$97.7 \quad$ AB269763 Yes

$98 \quad$ EF015477 No

$99 \quad$ AJ508366 No

98.7 DQ218322 Some

$98 \quad$ AF270950 ?

$98.5 \quad$ AY568495 ?

$99 \quad$ DQ230944 ?

$?$

DNA extracted from three atheromatous plaques obtained from routine carotid endarterectomy was amplified using broad-range 16S gene specific primers. 58 cloned 
products were sequenced, of which 56 could be identified by BLAST searches with $>97 \%$ identity to established bacterial species or genera. Listed also is an indication of whether these organisms are thought to be motile or otherwise. 


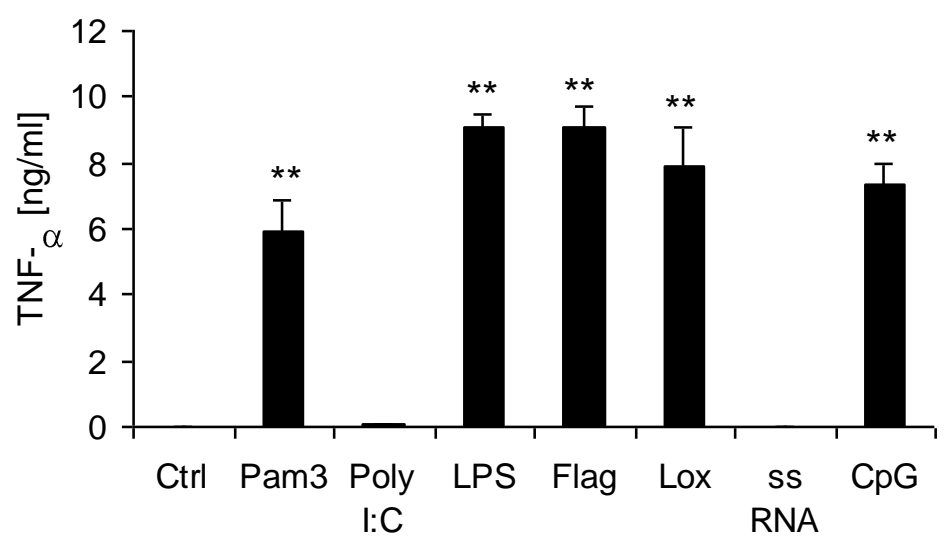

Figure 1 
A
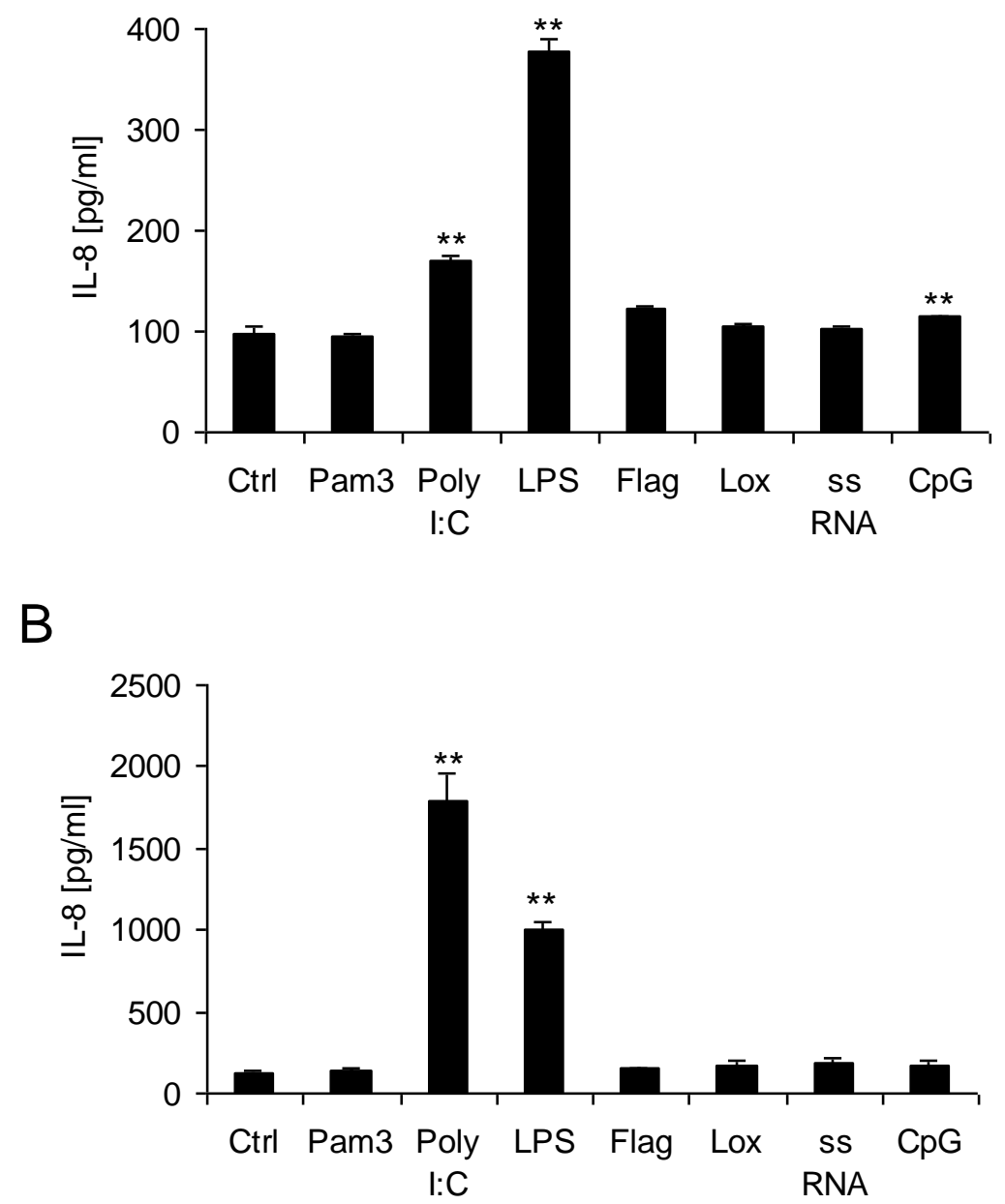

Figure 2 
A

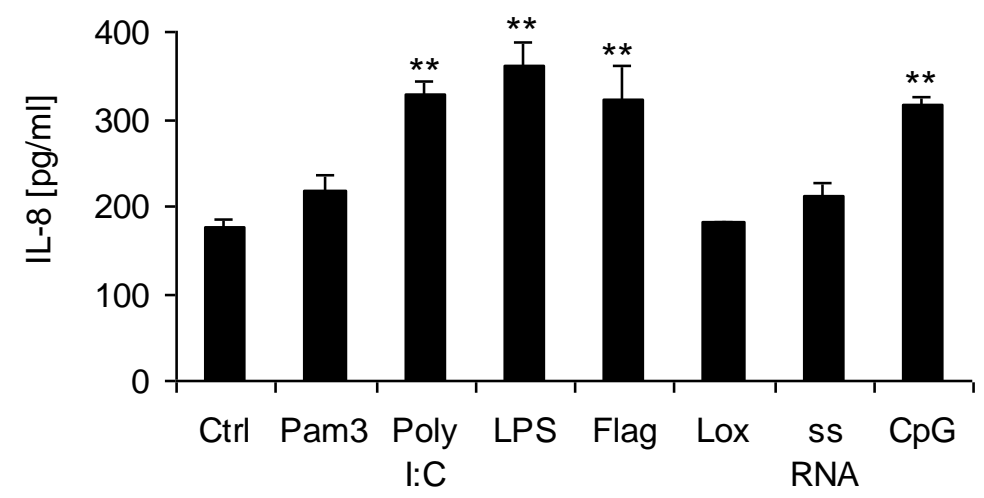

B

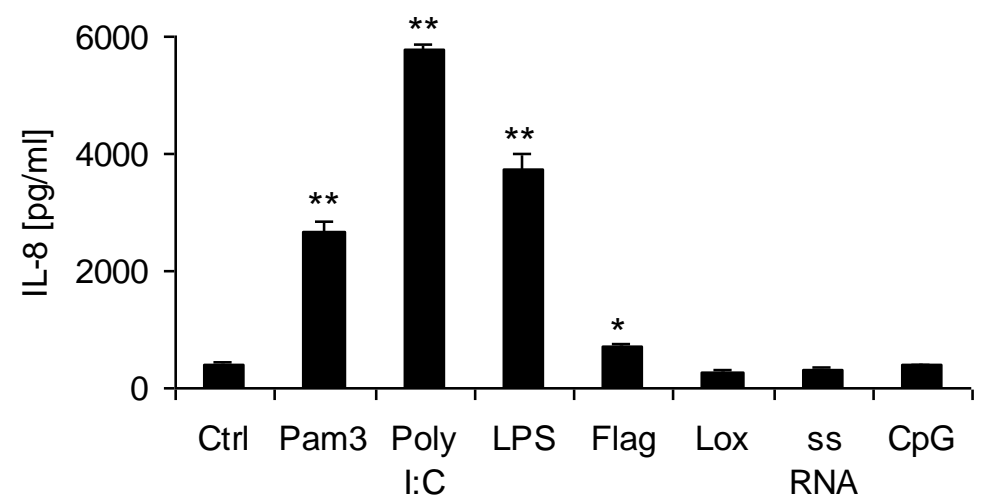

C

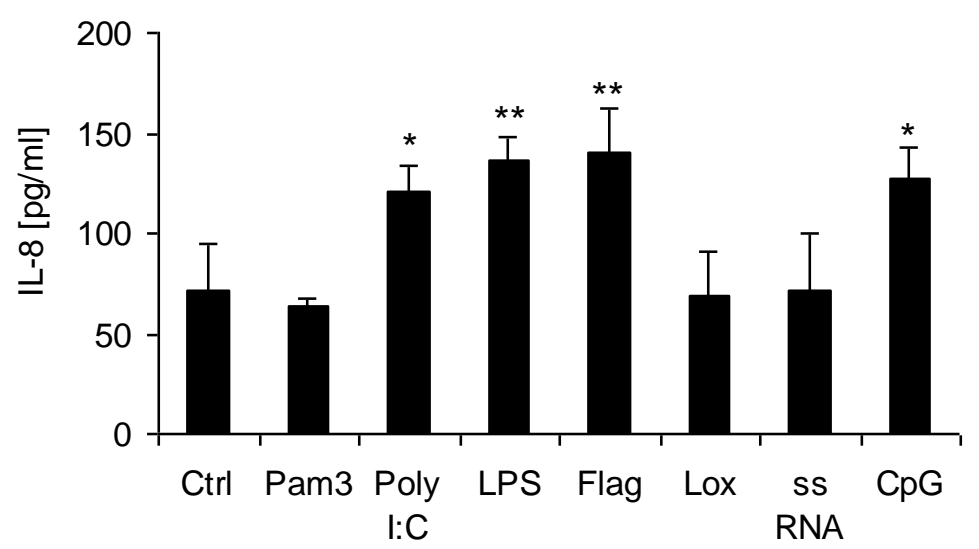

Figure 3 
A
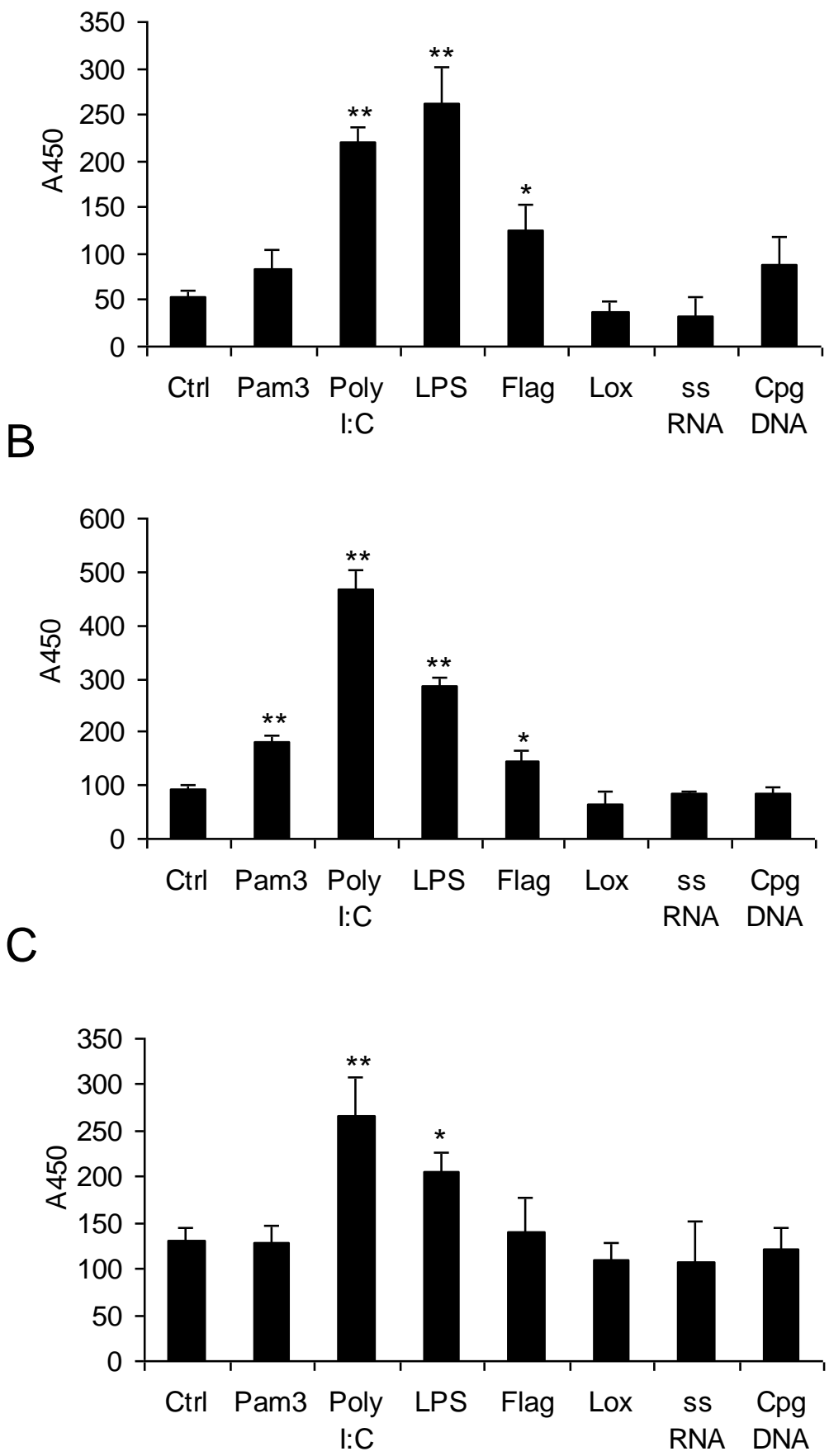

Figure 4 
$\begin{array}{llllllllll}\beta & 1 & 2 & 3 & 4 & 5 & 6 & 7 & 8 & 9\end{array}$

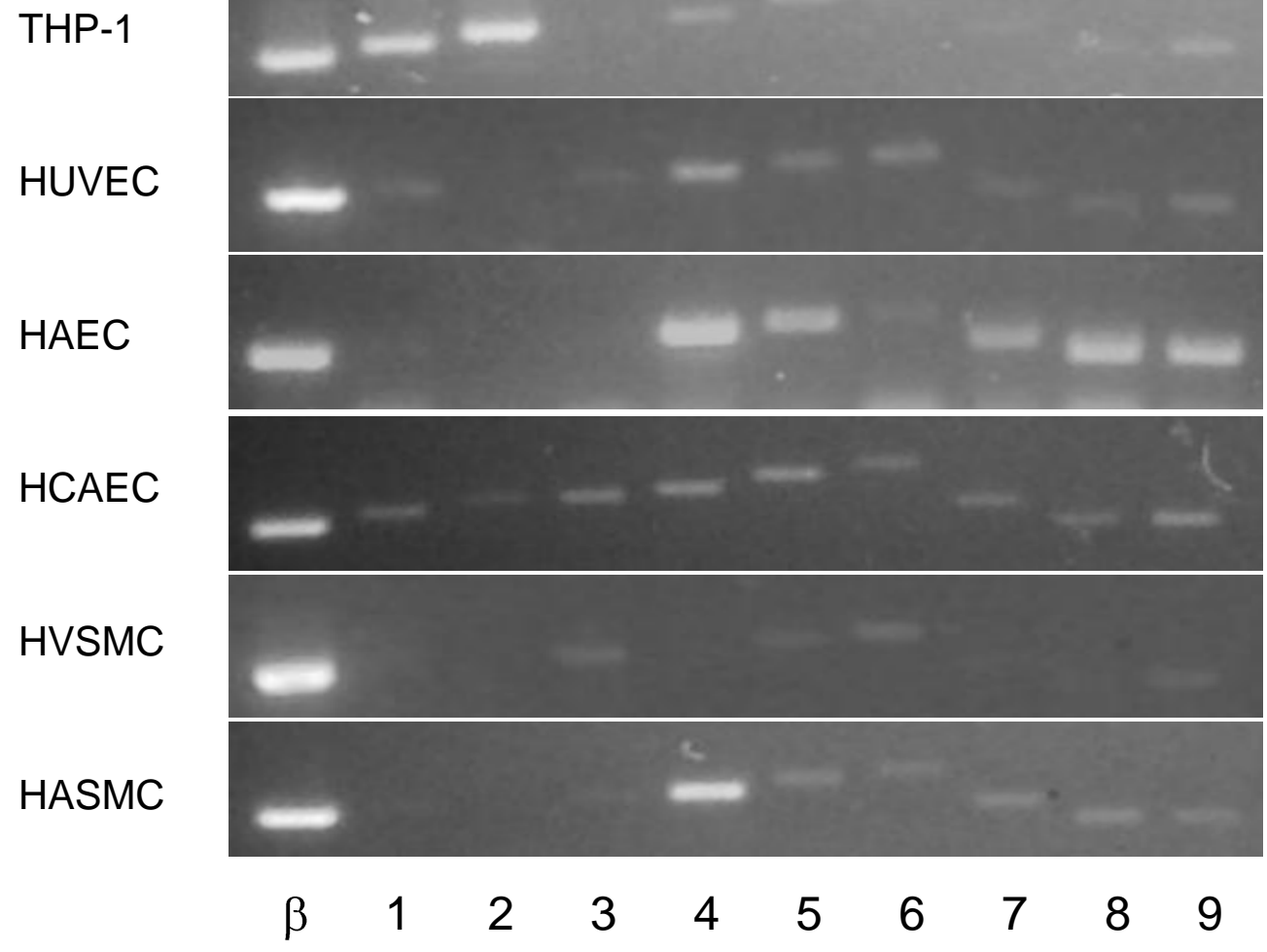

Figure 5 
A

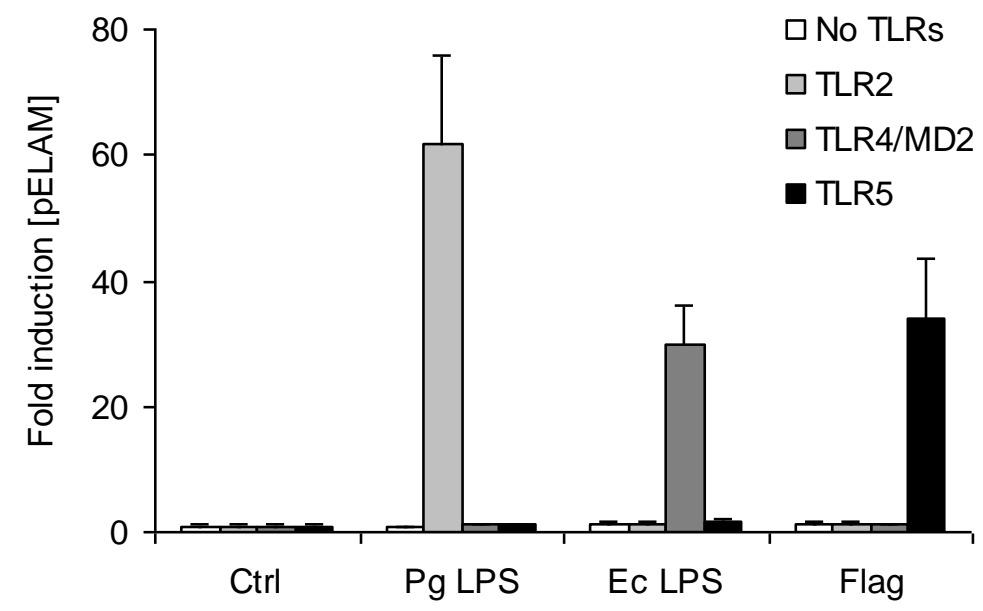

B

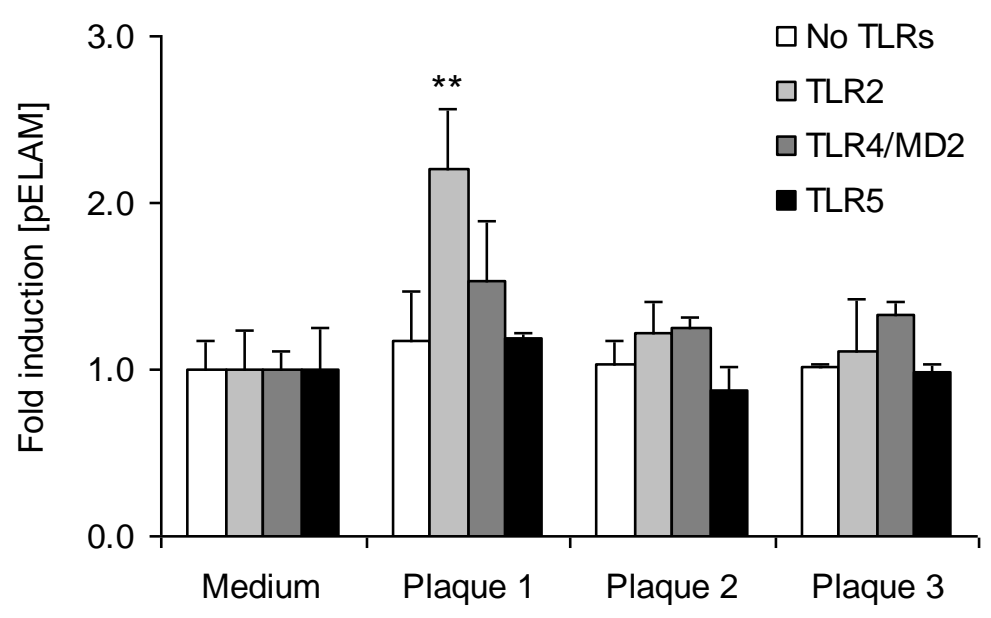

Figure 6 